\title{
Device Design and Test of Fatigue Behaviour of Expansion Anchor Subjected to Tensile Loads
}

\author{
Jinfeng $\mathrm{ZHANG}^{1, *}$, Hongbo $\mathrm{LUO}^{1}$ and Bo YANG ${ }^{1}$ \\ ${ }^{1}$ China Academy of Building Research, Beijing, China
}

\begin{abstract}
In order to study on the fatigue behaviour of expansion anchor (M16, grade 8.8) for overhead contact system in electrification railways, a set of safe, practical loading device is designed and a fatigue test campaign was carried out at structural laboratory of China Academy of Building Research on expansion anchor embedded in concrete block. The mobile frame of the loading device was designed well by finite-element simulation. According to some fatigue performance test of expansion anchor with different size and form, the device have been assessed experimentally its dependability. The results were found that no fatigue damage phenomenon occurred in all specimens after $2 \times 10^{6}$ cycles tensile fatigue test in this specific series. It shows that in the condition of medium level or slightly lower maximum stress limit and nominal stress range, expansion bolt has good fatigue resistance. The biggest relative displacement and the residual relative displacement after test $\left(\Delta \delta=\delta_{2}-\delta_{1}\right)$ was also strongly lower than the symbol of the fatigue test failure index of this specific series $(0.5 \mathrm{~mm})$ in the high cycle fatigue regime. The ultimate tension failures mode after fatigue tests in all tested samples take place in the concrete anchorage zone. The reduction range of the ultimate tensile strength properties of the anchorage system was not obvious, and the concrete was seen to be the weakest link of the system.
\end{abstract}

\section{Introduction}

There is an increasing interest for the fatigue behaviour of expansion anchor embedded in concrete as a result of wide project applications in curtain wall, subway tunnel and elevator. For example, in subway tunnel area expansion anchor used as connection system of mount catenary or overhead cables along electrification railway lines has subjected to vehicle vibration impulse load. Under the certain cycles, expansion anchor fatigue failure may occur. As a result, besides the static strength, the fatigue strength becomes the other important criterion for designing and applying this structural accessories. But at present, in China about the mechanical properties of expansion anchor research rarely reported[1-4], the test device and engineering test data are relatively lacking[5], and the national technical standard document has not been published either.

* Corresponding author:zhangjinfeng@emails.bjut.edu.cn 
For this purpose, a set of safe, practical and accurate loading device is designed to test expansion anchor embedded in concrete. And the device have been assessed experimentally its dependability by some fatigue performance test of expansion anchor specimens(M16,8.8Grade), which provides the basis for statistical analysis and evaluate fatigue performance of expansion anchor.

\section{Experiment}

\subsection{Design of loading device and specimens}

The loading device is made up of a movable frame, a rack and equipped with a computer-controlled hydraulic actuator (Fig. 1). In consideration of reducing the influence of movable frame own inertia force to the loading amplitude when applying pulsating tensile fatigue test, the finite element model of movable frame is established for keeping its own strength and stiffness under the premise of reducing movable frame weight, as shown in Fig. 2. Finally, after the finite element analysis, the beam part of frame is decided to lattice style through some different cross steel plate by welding, and the potential location of buckling is also enhanced in order to prevent the local buckling of the weak positions, such as connection node.
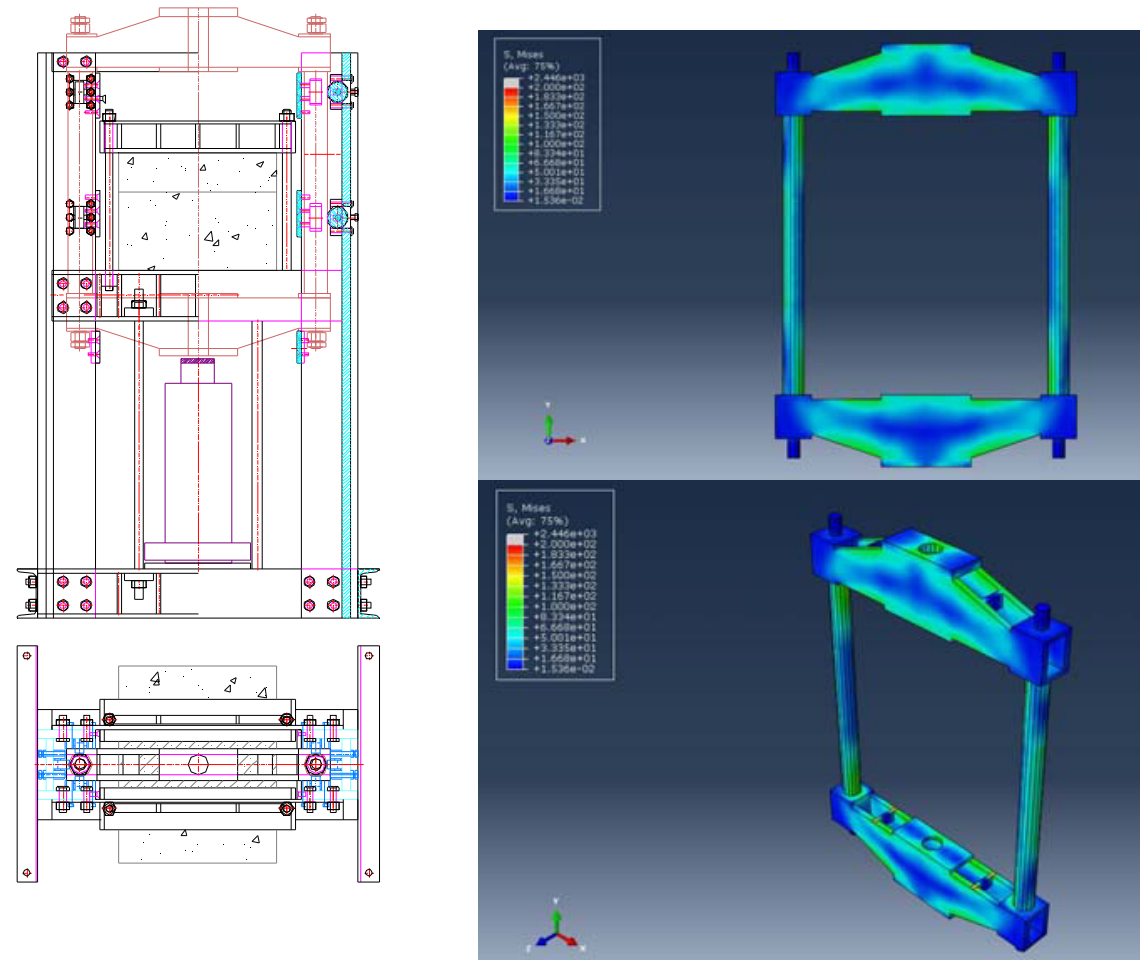

Fig. 1. Sketch of fatigue test device

Fig. 2. Stress diagram of movable frame under maximum designed load 
The main features of the loading device as follows: max. static load, $100 \mathrm{kN}$, max. dynamic load, $80 \mathrm{kN}$, max. frequency $10 \mathrm{~Hz}$. All test data were continuously monitored detecting applied forces, amplitude, frequency and number of cycles.

The concrete test specimens were prepared according to the following procedure: reinforcing cage binding, form erecting, recommended standard concreting and curing, and the expansion anchor were installed according to the following procedure: drilling, hole cleaning, installation of anchor bolt and exerting installation torque. The geometrical parameters characterizing the expansion anchor installed in concrete are shown in table 1. All expansion anchors are located in the central zone of the concrete block, and concrete blocks have a base of about $350 \mathrm{~mm} \times 350 \mathrm{~mm}$ and a height of about $200 \mathrm{~mm}$, which show in Fig.3.

Table 1 Anchorage Characteristics For M16 Expansion Anchor

\begin{tabular}{|c|c|c|c|c|c|c|c|}
\hline $\begin{array}{c}\text { Anchor } \\
\text { characteristi } \\
\text { cs }\end{array}$ & $\begin{array}{c}\text { Hole } \\
\text { diamete } \\
\mathrm{r} \\
{[\mathrm{mm}]}\end{array}$ & $\begin{array}{c}\text { Bolt } \\
\text { length } \\
{[\mathrm{mm}]}\end{array}$ & $\begin{array}{c}\text { Drill } \\
\text { depth } \\
{[\mathrm{mm}]}\end{array}$ & $\begin{array}{c}\text { Effective } \\
\text { anchorage } \\
\text { depth }[\mathrm{mm}]\end{array}$ & $\begin{array}{c}\text { Installatio } \\
\mathrm{n} \text { torque } \\
{[\mathrm{N} \cdot \mathrm{m}]}\end{array}$ & $\begin{array}{c}\text { Designed } \\
\text { concrete } \\
\text { strength } \\
{[\mathrm{Mpa}]}\end{array}$ & $\begin{array}{c}\text { Characteristi } \\
\mathrm{c} \text { anchor } \\
\text { resistance } \\
{[\mathrm{kN}]}\end{array}$ \\
\hline H-M16 & 16 & 140 & 115 & 95 & 110 & 30 & 43 \\
\hline F-M16 & 16 & 148 & 110 & 95 & 110 & 30 & 65 \\
\hline X-M16 & 16 & 125 & 90 & 80 & 80 & 30 & 29 \\
\hline
\end{tabular}
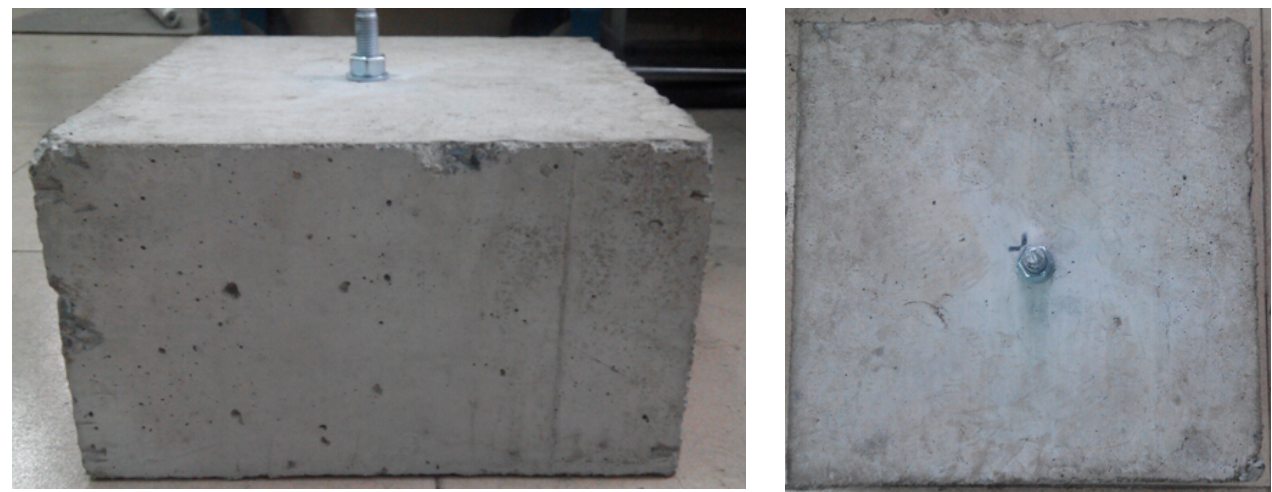

Fig. 3. Specimens photographs

\subsection{Method of experiment}

All experimental tests were performed on the test set-up, see Fig. 4. The concrete block was fixed by the built-up channel steel beam that on either side of the concrete block, and the load was applied to movable frame by hydraulic actuator, then the movable frame and tested expansion bolt was connected by loading rod and clamp, which realized the transmission of load finally.

The fatigue behavior of expansion bolt installed in concrete block was investigated by cyclic loading test of dynamic sine wave load. According to the design requirement of engineering, the maximum and minimum values of the applied tensile load $\left(P_{\max }, P_{\min }\right)$ was designed to $30 \%$ and $25 \%$ characteristic anchor resistance (5\%-fractile of results) under tension force, respectively.

In order to measure the relative displacement of expansion bolt and concrete block in the process of test, a displacement sensor was arrange on the loading clamp and concrete block surface. The symbol of the end of the test was set to the fatigue damage of expansion bolt was occurred, or the maximum relative displacement was exceed $0.5 \mathrm{~mm}$, or dynamic load number reached to the set number of cycles. 


\section{Results and Discussion}

The summarized test results are listed in Table 2-3 which give the specimen code, the maximum and minimum values of the applied tensile load $\left(P_{\max }, P_{\min }\right)$, the load range $\left(\Delta P=P_{\max }-P_{\min }\right)$, the nominal stress range $(\Delta \sigma)$, the frequency (f), the number of cycles $(\mathrm{N})$, the relative displacement before test $\left(\delta_{1}\right)$, the biggest relative displacement in test $\left(\delta_{\max }\right)$, the relative displacement after test $\left(\delta_{2}\right)$, the ultimate load after test $\left(\mathrm{F}_{\mathrm{m}}\right)$, the ratio of ultimate load after test to mean ultimate load (v) and the failure mode.

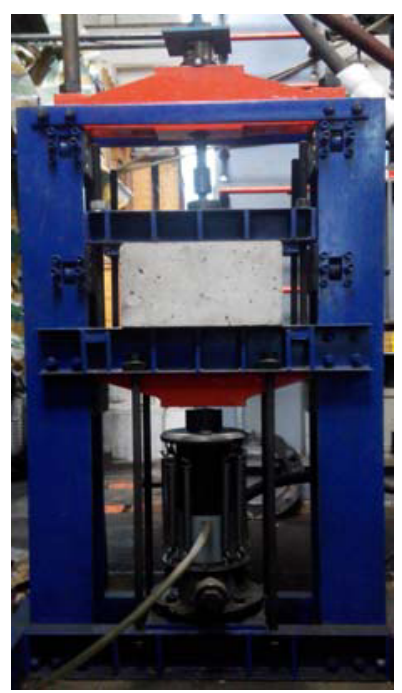

Fig. 4. Test set-up

Table 2 The Fatigue Test Conditions And Results

\begin{tabular}{|c|c|c|c|c|c|c|c|}
\hline Specimen & $\begin{array}{c}P_{\max } \\
{[\mathrm{kN}]}\end{array}$ & $\begin{array}{c}P_{\min } \\
{[\mathrm{kN}]}\end{array}$ & $\begin{array}{c}\Delta P \\
{[\mathrm{kN}]}\end{array}$ & $\begin{array}{c}\Delta \sigma \\
{[\mathrm{Mpa}]}\end{array}$ & $\begin{array}{c}\mathrm{f} \\
{[\mathrm{Hz}]}\end{array}$ & $\begin{array}{c}\mathrm{N} \\
{[\mathrm{cycles}]}\end{array}$ & Note \\
\hline H-M16-1 & 12.9 & 10.8 & 2.1 & 13.4 & 4 & 2000000 & nothing abnormal detected \\
\hline H-M16-2 & 12.9 & 10.8 & 2.1 & 13.4 & 4 & 2000000 & nothing abnormal detected \\
\hline F-M16-3 & 12.9 & 10.8 & 2.1 & 13.4 & 4 & 2000000 & nothing abnormal detected \\
\hline F-M16-2 & 19.5 & 16.2 & 3.3 & 21.0 & 6 & 2000000 & nothing abnormal detected \\
\hline F-M16-3 & 19.5 & 16.2 & 3.3 & 21.0 & 6 & 2000000 & nothing abnormal detected \\
\hline X-M16-1 & 8.7 & 7.2 & 1.5 & 9.6 & 6 & 2000000 & nothing abnormal detected \\
\hline X-M16-2 & 8.7 & 7.2 & 1.5 & 9.6 & 6 & 2000000 & nothing abnormal detected \\
\hline X-M16-3 & 8.7 & 7.2 & 1.5 & 9.6 & 6 & 2000000 & nothing abnormal detected \\
\hline
\end{tabular}


Table 3 The Displacement And Ultimate Load Results After Fatigue Test

\begin{tabular}{|c|c|c|c|c|c|c|}
\hline $\begin{array}{c}\text { Specime } \\
\mathrm{n}\end{array}$ & $\begin{array}{c}\delta_{1} \\
{[\mathrm{~mm}]}\end{array}$ & $\begin{array}{c}\delta_{\mathrm{max}} \\
{[\mathrm{mm}]}\end{array}$ & $\begin{array}{c}\delta_{2} \\
{[\mathrm{~mm}]}\end{array}$ & $\begin{array}{c}\mathrm{F}_{\mathrm{m}} \\
{[\mathrm{kN}]}\end{array}$ & $\begin{array}{c}v \\
{[\%]}\end{array}$ & Failure mode \\
\hline $\begin{array}{c}\text { H-M16- } \\
1\end{array}$ & 0.00 & 0.14 & 0.03 & 52.8 & 90.1 & $\begin{array}{c}\text { concrete cone } \\
\text { failure }\end{array}$ \\
\hline $\begin{array}{c}\text { H-M16- } \\
2\end{array}$ & 0.00 & 0.16 & 0.03 & 54.3 & 92.7 & $\begin{array}{c}\text { concrete cone } \\
\text { failure }\end{array}$ \\
\hline $\begin{array}{c}\text { H-M16- } \\
3\end{array}$ & 0.00 & 0.14 & 0.04 & 55.4 & 94.5 & $\begin{array}{c}\text { concrete cone } \\
\text { failure }\end{array}$ \\
\hline $\begin{array}{c}\text { F-M16- } \\
1\end{array}$ & 0.00 & 0.21 & 0.04 & 64.0 & 96.5 & $\begin{array}{c}\text { concrete cone } \\
\text { failure }\end{array}$ \\
\hline $\begin{array}{c}\text { F-M16- } \\
2\end{array}$ & 0.00 & 0.24 & 0.07 & 61.4 & 92.6 & $\begin{array}{c}\text { concrete cone } \\
\text { failure }\end{array}$ \\
\hline $\begin{array}{c}\text { F-M16- } \\
3\end{array}$ & 0.00 & 0.24 & 0.05 & 62.9 & 94.9 & $\begin{array}{c}\text { concrete cone } \\
\text { failure }\end{array}$ \\
\hline $\begin{array}{c}\text { X-M16- } \\
1\end{array}$ & 0.00 & 0.17 & 0.03 & 42.0 & 89.6 & $\begin{array}{c}\text { concrete cone } \\
\text { failure }\end{array}$ \\
\hline $\begin{array}{c}\text { X-M16- } \\
2\end{array}$ & 0.00 & 0.18 & 0.06 & 43.2 & 92.1 & $\begin{array}{c}\text { concrete cone } \\
\text { failure }\end{array}$ \\
\hline $\begin{array}{c}\text { X-M16- } \\
3\end{array}$ & 0.00 & 0.20 & 0.05 & 43.8 & 93.4 & $\begin{array}{c}\text { concrete cone } \\
\text { failure }\end{array}$ \\
\hline
\end{tabular}

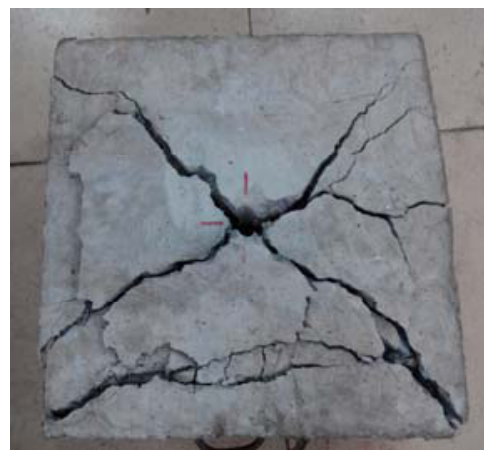

Fig. 5. Failure mode of specimens

All specimens were discovered that no fatigue damage phenomenon occurred after $2 \times 10^{6}$ cycles tensile fatigue test in different upper limit and lower limit of cyclic loading amplitude and frequency. It shows that in this load grade, expansion bolt has good fatigue resistance.

One worth noting was that all of the biggest relative displacement in test was not exceed $0.25 \mathrm{~mm}$, and the range of the residual relative displacement after test $\left(\Delta \delta=\delta_{2}-\delta_{1}\right)$ was $0.03 \mathrm{~mm}$ to $0.07 \mathrm{~mm}$, which is strongly in the safe side with respect to the symbol of the fatigue test failure index of this specific series $(0.5 \mathrm{~mm})$ in the high cycle fatigue regime. The other one worth noticing was the failure mode, which did not vary in all tested samples: the ultimate tension failures after fatigue tests did not take place in the steel rod but in the concrete anchorage zone(Fig. 5). And just 3.5\% to 10.4\% reduction of the ultimate tensile strength properties of the anchorage system was observed with respect to expansion bolt located in the centre of the concrete block, which demonstrates the ultimate tensile strength of the specimens after $2 \times 10^{6}$ cycles fatigue test had no obvious effect in the low stress level. Again, the concrete was seen to be the weakest link of the system. 


\section{Conclusions}

Fatigue test results obtained from expansion bolt (M16, grade 8.8) embedded in concrete are documented, And the conclusions can be summarized as follows:

(1) There was no fatigue damage phenomenon occurred in all specimens after $2 \times 10^{6}$ cycles tensile fatigue test in different upper limit and lower limit of cyclic loading amplitude and frequency. It shows that in the condition of medium level or slightly lower maximum stress limit and nominal stress range, expansion bolt has good fatigue resistance.

(2) The biggest relative displacement in test was not exceed $0.25 \mathrm{~mm}$, and the range of the residual relative displacement after test $\left(\Delta \delta=\delta_{2}-\delta_{1}\right)$ was not exceed $0.01 \mathrm{~mm}$, which is strongly lower than the symbol of the fatigue test failure index of this specific series $(0.5 \mathrm{~mm})$ in the high cycle fatigue regime.

(3) The ultimate tension failures mode after fatigue tests in all tested samples take place in the concrete anchorage zone. And the reduction range of the ultimate tensile strength properties of the anchorage system was not obvious, and the concrete was seen to be the weakest link of the system.

\section{Acknowledgement}

The authors gratefully wish to acknowledge the financial support of the Youth Foundation of China Academy of Build Research.

\section{References}

1. D.Y. Bi, Experimental Study on the pullout anchorage performance of halfen cast-in channel [D]. Shanghai Tongji University, 2009.

2. J.F. Zhang, J. T. Wang, B. Yang, Experiment study on the tension capacity performance of the groove embedded parts, Construction Quality. 32 (2014) 30-32.

3. S.M. Xu, D.Y. Zhou, D.Y. Bi, Test study on tensile behavior of cast-in channels, Structural Engineers. 26 (2010) 111-116.

4. L.H. Bo, J.F. Zhang, W.Z. Wang, Test research on the tensile fatigue performance of the channel pre-embedment, Construction Quality. 32 (2014) 31-33.

5. P. Lazzarin, J. Grun, F. Mutignani, R. Ronchi, Fatigue behaviour of bonded anchors subjected to tensile loads, Mat.-wiss.u. Werkstofftech. 41 (2010) 372-377. 